\title{
الوضع الراهن للموارد الاقتصادية في دول شمال إفريقيا
}

\author{
جراح عبد القادر أحمد برجس
}

باحث دكتوراه -معهد البحوث والدراسات الأفريقية ودول حوض النيل- جامعة اسوان.

$$
\text { طلعت حافظ اسماعيل }
$$

استاذ الاقتصاد الزراعي المتفرغ- كلية الزراعة - جامعة اسيوط.

$$
\text { احمد ابراهيم محمد أحمد }
$$

استاذ الاقتصاد الزراعي المساعد - كلية الزراعة بأسيوط- جامعة الازهر. 


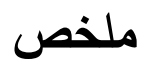

الوضع النسبي للموارد الاقتصادية تبين أن توزيع الموارد الأرضية لدول شمال أفريقيا

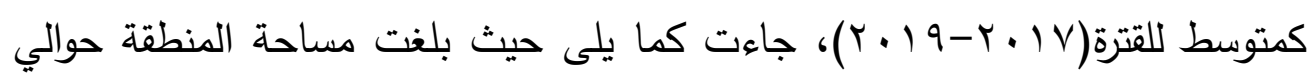
TVArOA ألف هكتار وبلغت مساحة الأراضي الزراعية لمنطقة حوالي 1 lOVO.VT ألف هكتار بنسبة بلغت حوالي IY\% من اجمالي المساحة الأرضية للمنطقة، وعند دراسة المساهمة النسبية للعمالة البشرية المشتغلة في الزراعة والخدمات

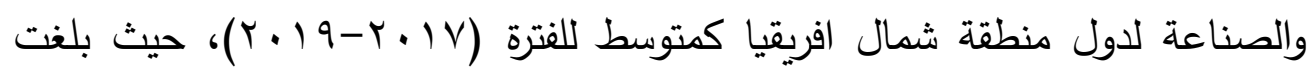
نسبة العاملون بقطاع الزراعة كمتوسط لدول المنطقة نحو .0 \%، بينما بلغت نسبة العاملون في قطاع الخدمات كمتوسط لدول المنطقة نحو ب\%\%، في حين بلغت نسبة العاملون في قطاع الصناعة كمتوسط لدول المنطقة نحو \%ro\%. الكلمات المفتاحية: الموارد الاقتصادية، دول شمال افريقيا

Current Status of Economic Resources in North African Countries

\section{Summary:}

The results of the research indicate when studying the relative position of economic resources: that the distribution of land resources in North Africa is an average for the period (20172019), as the area's area reached about 678359 thousand hectares, and the area of agricultural land in the region amounted to about 
141575.76 thousand hectares, at a rate of about $21 \%$ of the total area. When studying the relative contribution of human labor working in agriculture, services and industry for North African countries as an average for the period (2017-2019

When studying the relative importance of renewable water resources for North African countries as an average for the period, Egypt occupied the first place with an amount amounting to about 57.5 billion $\mathrm{m} 3$, with a ratio of about $50.05 \%$ of the total water resources in the region, followed by Morocco with an amount of about 29 billion $\mathrm{m} 3$ With a rate of about $25.24 \%$, followed by Algeria with a quantity of about 11.67 billion $\mathrm{m} 3$, a rate of about $10.16 \%$.

When studying the per capita share of some resources and economic indicators, the results show that the per capita share of arable land in North African countries decreased at a significant rate of about 0.003 hectares / person annually equivalent to about $2.21 \%$ of the average per capita share of arable land for the region during The study period.

With regard to water resources: it was found that the per capita share of the water resources of North African countries decreased at a significant rate of about 0.011 hectares / person per year equivalent to about $1.64 \%$ of the average per capita share of the water resources of the region during the study period 
مقدمة:

تعد إفريقيا أغنى تجمع للموارد الطبيعية مثل النفط والنحاس والماس والليثيوم والذهب وغابات الأخشاب الصلبة والفواكه الاستوائية، وتشير التقديرات إلى أن ـ٪\% من الموارد المعدنية المستخرجة من الأرض موجودة في القارة الإفريقية، با ٪ من النفط المنتج في العالم يأتي من إفريقيا، كما تمتلك إفريقيا أكبر احتياطيات للمعادن الثمينة في العالم، وثلثي مجموع الأراضي الزراعية غير المستغلة في العالم توجد في إفريقيا، وهذه الاحتياطيات من الثروات الطبيعية، تسهم بشكل كبير في دعم اقتصاديات البلدان الإفريقية، وتعزيز فرص النمو ودعم مؤشرات التنمية في القارة ، وتعد قارة أفريقيا ثاني أكبر قارات العالم من حيث المساحة وعدد السكان، وتأتي في المرتبة الثانية بعد آسيا، حيث تبلغ مساحتها ؟, •بr مليون كيلومتر مربع (V, I ا مليون ميل مربع)، وتتضمن هذه المساحة الجزر المجاورة، وهي تغطي ج\% من إجمالي مساحة سطح الأرض، وتشغل ع. . r \% من إجمالي مساحة اليابسة. (اميم-1) وتضم دول الثمال الافريقي كل من: مصر وليبيا وتونس والجزائر والمغرب وموريتانيا، وترتبط دول الشمال الاقريقي بروابط ثقافيه واجتماعيه واقتصاديه، فضلا عن انضمامها لعدة منظمات إقليميه مشتركة من أهمها: الجامعة العربية ومنظماتها الفرعية، والاتحاد الافريقي، واتحاد المغرب العربي فماعدا مصر، وتتميز هذه الدول 
بوقوعها في حيز جغرافي واحد، مما يجعل كل ما سبق أحدى عوامل الشراكة الاقتصادية والادارة المتكاملة للموارد الاقتصادية والتعاون الاقليمي لهذه الدول، ولآجل تعضيد ذلك، كان من الأهمية دراسة الوضع الراهن للموارد الاقتصادية لدول الثمال الافريقي. مثكلة البحث: رغم المقومات الاقتصادية والثقافية التي تحظى بها دول الثمال الافريقي، واشتراكها في العديد من المقومات الثقافية والاجتماعية كاللغة والثقافة والتاريخ المشترك والعديد من المنظمات الإقليمية الاقتصادية منها والسياسية ، الا أن هذه المقومات حتى الان لم تستغل الاستغلا الامثل، ويظهر ذلك جلياً في ضعف العمل المشترك وتفاوت نصيب الفرد من الموارد الاقتصادية، والاختلاف النسبي للرفاهية الاقتصادية لهذه الدول، فكان من الأهمية زيادة الاهتمام بالعمل المشترك بين دول الثمال الاقريقي، وزيادة فرص الاستغلال المشترك والادارة المتكاملة للموارد الاقتصادية في المنطقة.

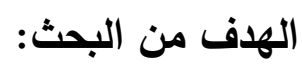
استهدف البحث القاء الضوء علي الوضع الراهن للموارد الاقتصادية في الثمال الافريقي من خلال... دراسة: 1- الوضع النسبي للموارد الاقتصادية في دول الثمال الافريقي. $($ ror $)$ 
r- تطور نصيب الفرد من بعض الموارد والمؤشرات الاقتصادية في دول الشمال الافريقي.

الطربقة البحثية ومصادر البيانات:

اعتمدت البحث على التحليل الإحصائي الوصفي والكمي في توضيح ودراسة الفروق

النسبية للموارد والمؤشرات الاقتصادية لدول الشمال الافريقي، واستخدام بعض المقاييس الإحصائية لتحقيق أهداف البحث، ولقد اعتمدت البحث على البيانات المنشورة من قبل الجهات العالمية المختصة ، كالبنك الدولي ، وموقع إحصاءات منظمة الاغذية والزراعة (FAO STAT)، وبعض الإصدارات العلمية والجهات المختصة الاخرى. مناقشة النتائج: اولا- التقارب الجغرافي والمكاني لاول شمال افريقيا: توضح الخريطة التالية: موقع دول الشمال الافريقي من محيطها الافريقي، حيث تتميز هذه المنطقة بموقع هام يعتبر معبر وامتداد للقارة الأفريقية نحو قارتي اسيا واروبا، ويعتبر هذا الموقع عامل جزب لكثير من الاستثارات العالمية والاهتمام الاقتصادي والسياسي بهذه المنطقة من القاره الأفريقية من قبل القوى العالمية 
والإقليمية، ومنطقة شمال افريقيا وتضم 7 دول هي ومصر وليبيا وتونس والجزائر

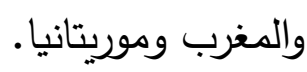

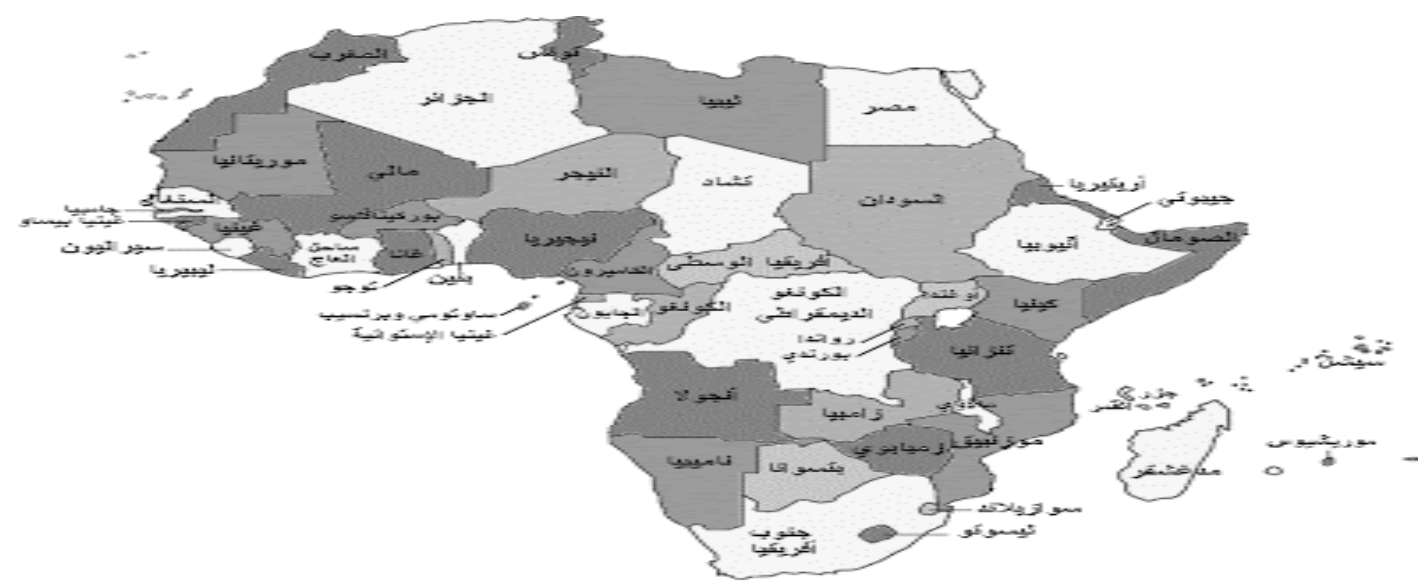

تثمل الموارد الاقتصادية العديد من الاشكال المتعارف عليها ، الا أن الموارد الأرضية والعمالة والموارد المائية تعتبر من أهم هذه الموارد، لكونها أهم المدخلات في العمل الاقتصادي لا غلب الدول وخاصة النامية منها . لذا سوف يتناول هذا الجزء من البحث ، التوصيف النسبي لهذه الموارد في دول شمال افريقيا ، باعتبارها من أهم المقومات الاقتصاديه لهذه الدول . أ- - الوضع الراهن للموارد الارضية في دول شمال افريقيا: يوضح الجدول رقم(1) توزيع الموارد الأرضية لدول شمال أفريقيا كمتوسط للقترة

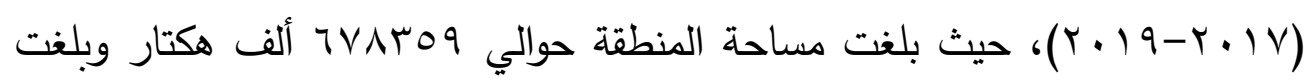

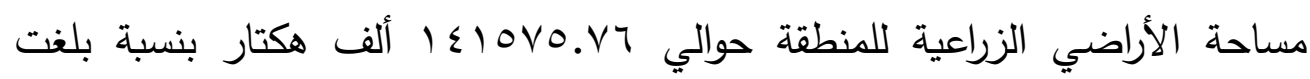


حوالي اYY\% من اجمالي المساحة الأرضية للمنطقة كما موضح بالشكل رقم( )، في حين بلغت مساحة الأراضي القابلة للزراعة حوالي r, r ا ـ r ألف هكتار بنسبة بلغت حوالي r\% من إجمالي المنطقة، في حين بلغت مساحة الأراضي الأخرى حوالي

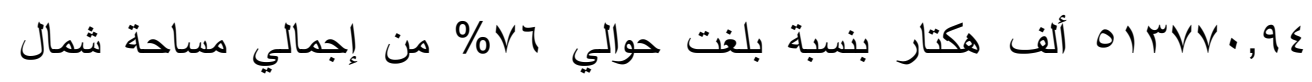
أفريقيا، وشغلت المرتبة الأولى من حيث المساحة الجزائر بنسبة بلغت نحو ه广\% من مساحة شمال أفريقيا ، يليها ليبيا بنسبة بلغت نحو بr\% ، بينما جاءت مصر وموريتانيا في المرتبة الثالثة بنسبة بلغت نحو 01\% كما يوضح الثكل رقم (ץ) .

شكل رقم (1) توزيع المساحات حسب نوعها لدول شمال افريقيا خلال

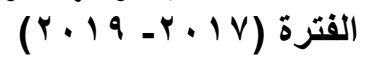
الأراضي الأخرى $\square$ الأراضي القابلة للزراعة ( الف هكتار) \ الأرض الزراعية ( الف هكتار)

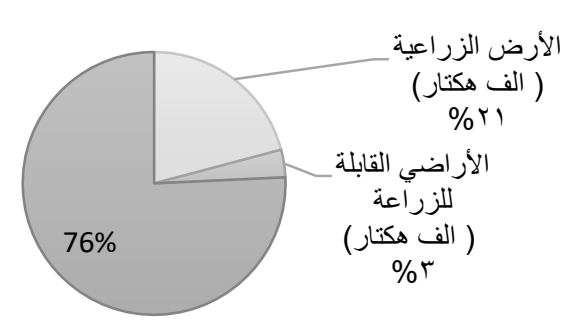

المصدر: جمعت وحسبت من : جدول رقم (1).

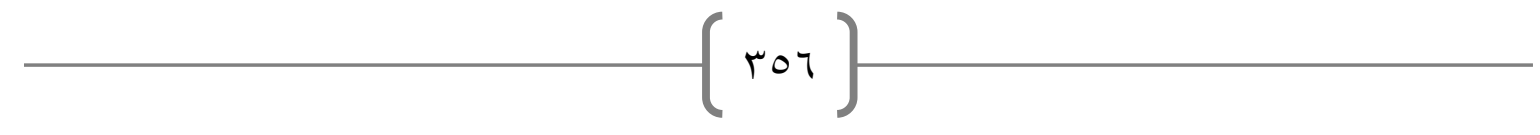




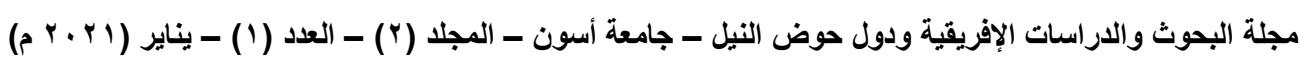

شكل رقم (r) نسب توزيع المساحه لدول شمال افريقيا خلال

متوسط الفترة

$(r+19-r+1 v)$

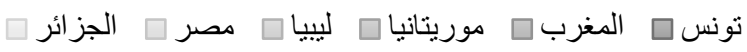

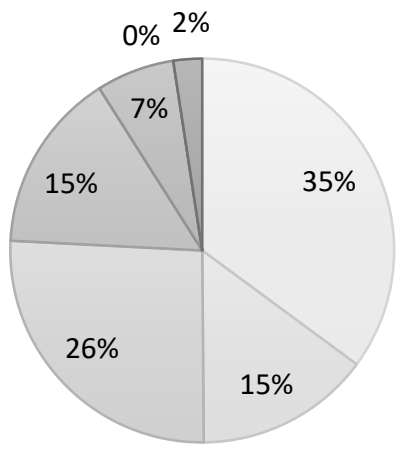

المصدر: جمعت وحسبت من : جدول رقم (1).

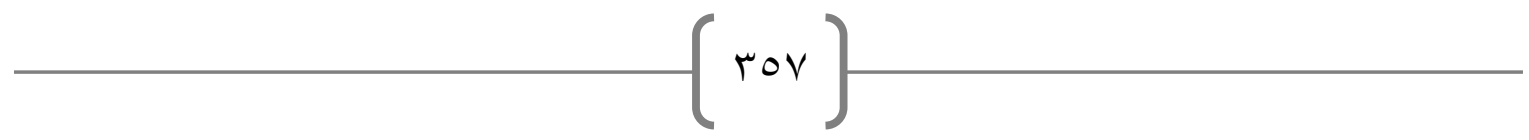


جدول رقم (1) الموارد الأرضية في دول شمال افريقيا كمتوسط للفترة (V •r$(r \cdot 19$ المصدر: جمعت وحسبت من: قاعدة بيانات البنك الدولي، مؤشرات التنمية الاقتصاديه، ، ب. r. ب- الوضع الراهن للعمالة البثرية في دول شمال افريقيا: يوضح الجدول رقم (Y) المساهمة النسبية للعمالة البشرية المشتغلة في الزراعة

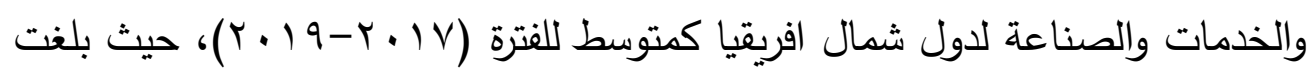
نسبة العاملون بقطاع الزراعة كمتوسط لدول المنطقة نحو .0\%، بينما بلغت نسبة العاملون في قطاع الخدمات كمتوسط لدول المنطقة نحو بr\%، في حين بلغت نسبة

\begin{tabular}{|c|c|c|c|c|}
\hline الأراضي الأخرى & الأراضي القابلة للزراعة & ألأرض الززاعية & (ألف هكتار) & \\
\hline 93541.90 & 2727.56 & 3875.55 & 100145.00 & مصر \\
\hline 158963.47 & 1679.74 & 15310.79 & 175954.00 & ليبيا \\
\hline 3261.59 & 2913.01 & 10186.41 & 16361.00 & تونس \\
\hline 188713.12 & 7433.56 & 42027.33 & 238174.00 & الجزائر \\
\hline 6372.99 & 7812.67 & 30469.34 & 44655.00 & المغرب \\
\hline 62917.89 & 445.76 & 39706.35 & 103070.00 & موريتانيا \\
\hline 513770.94 & 23012.30 & 141575.76 & $\begin{array}{c}678359.0 \\
0\end{array}$ & الإجمالي \\
\hline
\end{tabular}


مجلة البحوث والدراسات الإفريقية ودول حوض النيل - جامعة أسون - المجلد (r) - العدد ( ) - يناير ( Y • r م)

العاملون في قطاع الصناعة كمتوسط لدول المنطقة نحوهب\%، كما موضح بشكل رقم (r)، واحتلت المرتبة الأولى من حيث العاملون في قطاع الزراعة دولة ليبيا والجزائر

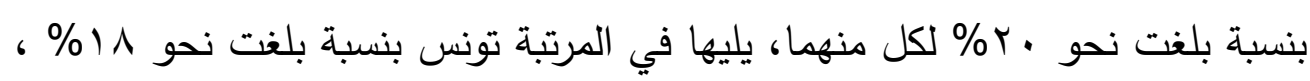
يليها مصر بنسبة بلغت نحو 7 (\% كما موضح بالثكل رقم (ع).

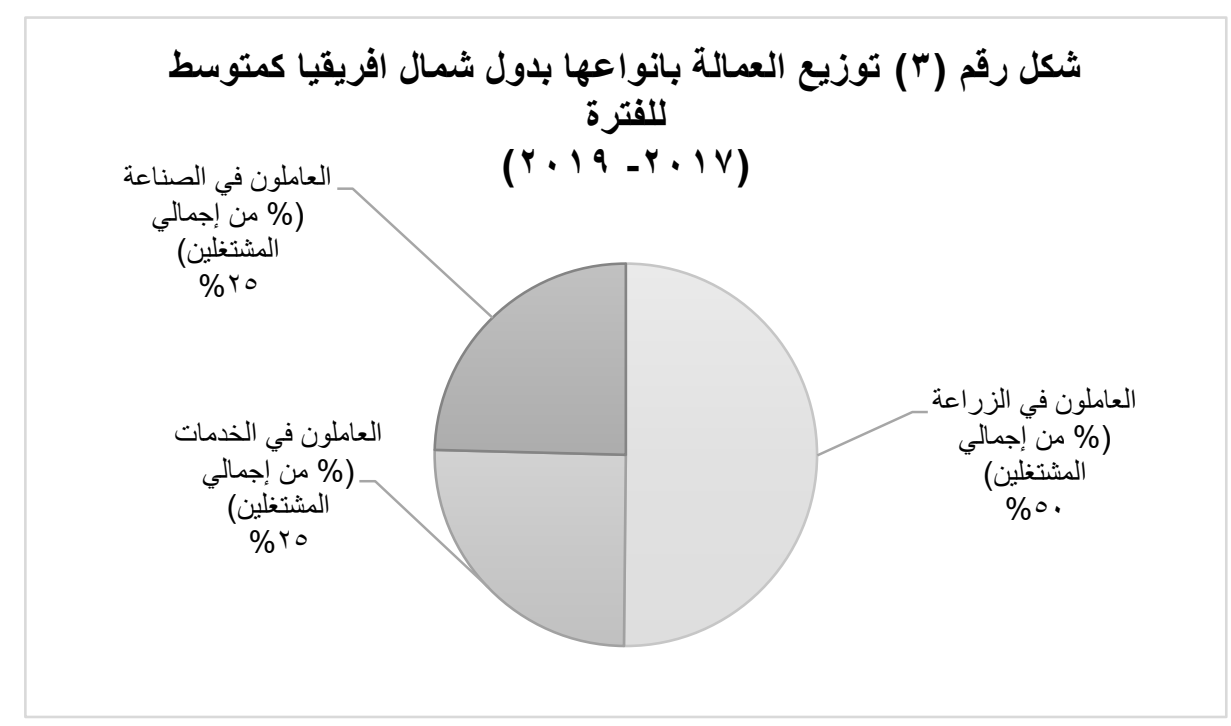

(ץ) المدر : جمعت وحسبت من : جدول رقم (r).

المصدر : جمعت وحسبت من : جدول رقم (ץ). 
شكل رقم (؛ ) توزيع العمالة الزراعية بدول شمال افريقيا كمتوسط للفترة $(r+19-r+1 v)$

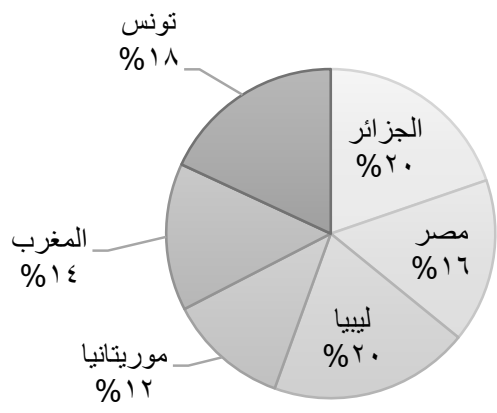

المصدر : جمعت وحسبت من : جدول رقم (ץ). 
جدول رقم (ץ) - الاهمية النسبية للعمالة المشتفلة في الزراعة والخدمات والصناعة دول

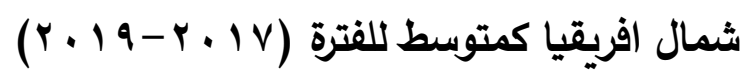

\begin{tabular}{|c|c|c|c|}
\hline 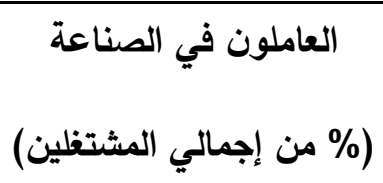 & 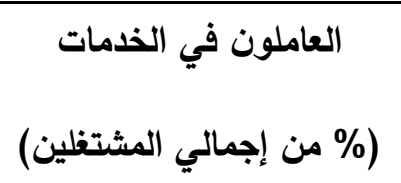 & (العاملون في الزراعة & الدوله \\
\hline 27.68 & 23.79 & 48.53 & مصر \\
\hline 21.92 & 18.91 & 59.17 & ليبيا \\
\hline 32.55 & 13.03 & 54.42 & تونس \\
\hline 30.73 & 9.86 & 59.41 & الجزائر \\
\hline 21.71 & 34.69 & 43.60 & المغرب \\
\hline 12.94 & 51.27 & 35.78 & موريتانيا \\
\hline 21.08 & 21.65 & 42.99 & المتوسط \\
\hline
\end{tabular}

المصدر: جمعت وحسبت من: قاعدة بيانات البنك الدولي، مؤشرات التنمية الاقتصاديه، ·. .r.

ج- الوضع الراهن للموارد المائية المتجددة في دول شمال افريقيا:

يوضح الجدول رقم (r) الأهمية النسبية للموارد المائية المتجددة دول شمال افريقيا كمتوسط

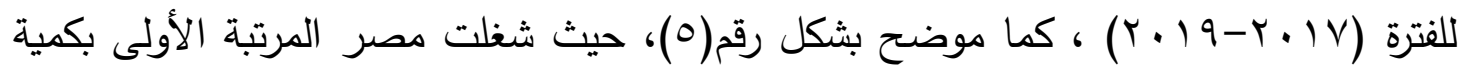
بلغت حوالي OV,0 مليار م بنسبة بلغت نحو 0., . 0\% من إجمالي الموارد المائية بالمنطقة،

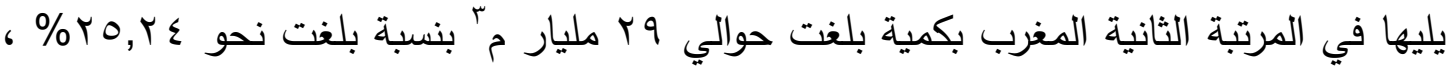

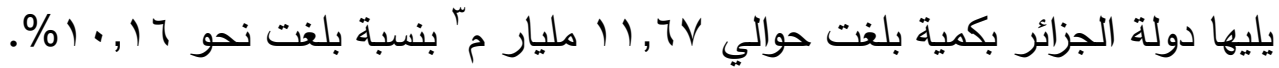

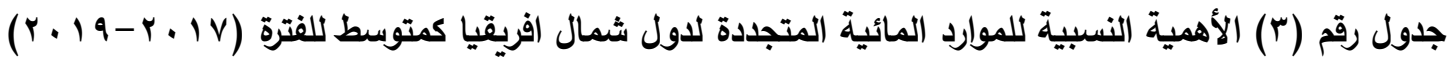


جراح عبد القادر أحمد برجس وآخرون، الوضع الراهن للموارد الاقتصادية في دول شمال افريقيا

\begin{tabular}{|c|c|c|}
\hline$\%$ & ( مليار متر مكعب) & \\
\hline 50.05 & 57.50 & مصر \\
\hline 0.61 & 0.70 & ليبيا \\
\hline 4.01 & 4.61 & تونس \\
\hline 10.16 & 11.67 & الجزائر \\
\hline 25.24 & 29.00 & المغرب \\
\hline 9.92 & 11.40 & موريتانيا \\
\hline 100.00 & 114.88 & الإجمالي \\
\hline
\end{tabular}

المصدر: قاعدة بيانات المنظمة العالمية للأغذية والزراعة، FAO stat ، . . . F.

شكل رقم(0) الاهمية النسبية للموارد المائية المتجددة في دول شمال افريقيا كمتوسط

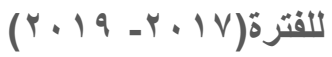

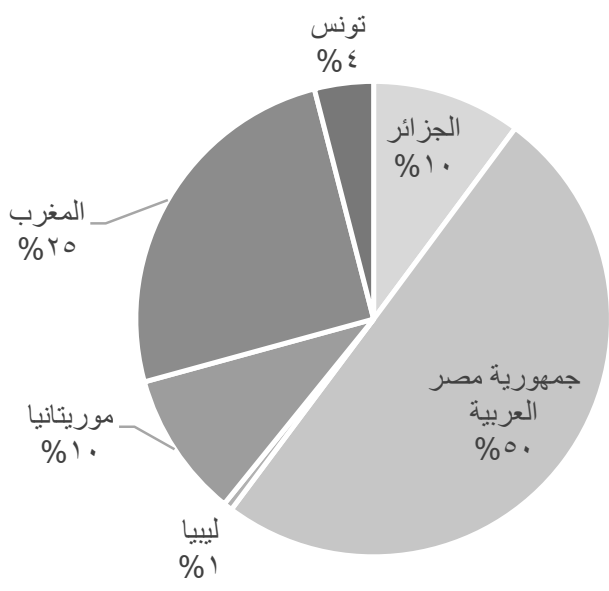

المصدر : جمعت وحسبت من : جدول رقم (r).

ثالثا- تظور نصيب الفرد من بعض الموارد والمؤشرات الاقتصادية في دول شمال افريقيا: يعتبر نصيب الفرد من الموارد والإجماليات الاقتصادية القومية مؤشراً هام، يوضتح مدى تقدم الدول في استغلال مواردها الاقتصادية، وينعكس ذلك علي الرفاهية الاقتصادية لشعوبها، وسوف يلقى هذا الجزء من البحث الضوء علي نصيب الفرد من سكان دول شمال افريقيا من الموارد 
الأرضية (الاراضي القابلة للزراعة والاراضي الزراعية)، ونصيب الفرد من الموارد المائية المتجددة، وكذلك نصيب الفرد من الدخل القومي الصافي لإجمالي دول الثمال الأفريقي خلا

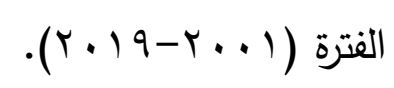

أ- تطور نصيب الفرد من الموارد الأرضية:

يوضح الجدول رقم (ع) تطور نصيب السكان من الموارد الأرضية لدول شمال افريقيا،

حيث بلغت أدنى حد لنصيب الفرد من الأراضي القابلة للزراعة حوالي با ا, . هكتار/ فرد

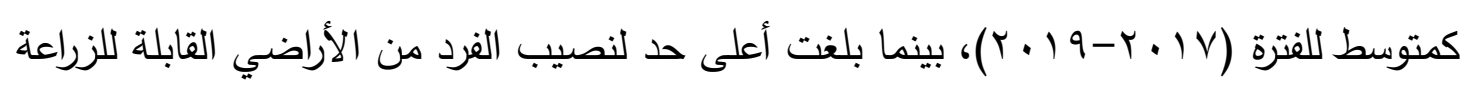
حوالي (7ا.. هكتار / فرد عام | ... ، بمتوسط بلغ بسا,. هكتار/فرد مما يدل على انخفاض نصيب الفرد بمرور الزمن وتأثير الزيادة السكانية علي نصيب الفرد من تلك المورد ، كما توضح المعادلة بالجدول(0) أن نصيب الفرد من الأراضي القابلة للزراعة في دول شمال افريقيا تناقص بمعدل معنوي بلغ حوالي r ..,. هكتار/فرد سنويا يعادل حوالي (Y,Y\% من متوسط نصيب الفرد من الأراضي القابلة للزراعة للمنطقة خلال فترة الدراسة، ويشير معامل التحديد) (إلى أن 91\% من التغيرات الحادثة في نصيب الفرد من الأراضي القابلة للزراعة ترجع إلى العوامل التي يعكسها متغير الزمن. وعند دراسة نصيب الفرد من الأراضي الزراعية يبين نفس الجدول، انه سجل أدنى حد له عام

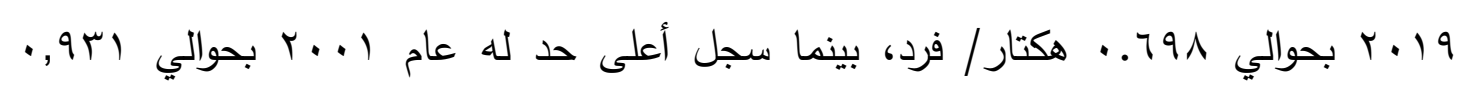
هكتار/ فرد ، بمتوسط بلغ 10, · هكتار/فرد، مما يدل على انخفاض نصيب الفرد بمرور الزمن وتأثير الزيادة السكانية علي نصيب الفرد من تلك المورد، كما توضح المعادلة بالجدول (0) أن نصيب الفرد من الأراضي الزراعة لمنطقة شمال افريقيا تناقص بمعدل معنوي بلغ حوالي 
ب ا .,. هكتار/فرد سنويا يعادل حوالي 7, ا \% من متوسط نصيب الفرد من الأراضي الزراعة للمنطقة خلال فترة الدراسة، ويشير معامل التحديد(R²) إلى أن 99\% من التغيرات الحادثة في نصيب الفرد من الأراضي الزراعة لمنطقة شمال افريقيا ترجع إلى العوامل التي يعكسها متغير

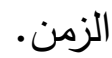
جدول رقم(؛) تطور نصيب السكان من بعض الموارد والمؤشرات في دول شمال

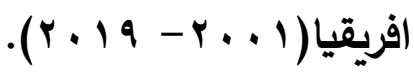

\begin{tabular}{|c|c|c|c|c|}
\hline \multicolumn{4}{|c|}{ شمال أفريقيا } & \\
\hline نصيب الفرد من الاخل & نصيب الفرد من الموارد & الألزراضية & الأراضي القابلة للزراعة & \\
\hline 11594.67 & 0.77 & 0.931 & 0.161 & 2001 \\
\hline 8870.36 & 0.76 & 0.917 & 0.158 & 2002 \\
\hline 10445.86 & 0.75 & 0.907 & 0.160 & 2003 \\
\hline 11745.09 & 0.74 & 0.896 & 0.152 & 2004 \\
\hline 13656.94 & 0.73 & 0.883 & 0.146 & 2005 \\
\hline 15199.75 & 0.72 & 0.869 & 0.144 & 2006 \\
\hline 18029.75 & 0.70 & 0.856 & 0.141 & 2007 \\
\hline 21743.74 & 0.69 & 0.844 & 0.140 & 2008 \\
\hline 19437.98 & 0.68 & 0.830 & 0.138 & 2009 \\
\hline 21208.93 & 0.67 & 0.818 & 0.135 & 2010 \\
\hline 18390.30 & 0.66 & 0.803 & 0.132 & 2011 \\
\hline 23119.90 & 0.65 & 0.789 & 0.131 & 2012 \\
\hline 22472.88 & 0.63 & 0.776 & 0.129 & 2013 \\
\hline 19993.42 & 0.62 & 0.762 & 0.126 & 2014 \\
\hline 17258.94 & 0.61 & 0.748 & 0.125 & 2015 \\
\hline 16875.63 & 0.60 & 0.733 & 0.122 & 2016 \\
\hline
\end{tabular}




$$
\text { مجلة البحوث و الدراسات الإفريقية ودول حوض النيل - جامعة أسون - المجلد (r) - العدد ( ) - يناير ( r r م م) }
$$

\begin{tabular}{|l|l|l|l|l||}
\hline 17093.00 & 0.59 & 0.722 & 0.118 & 2017 \\
\hline 18764.78 & 0.58 & 0.709 & 0.116 & 2018 \\
\hline 22039.38 & 0.57 & 0.698 & 0.113 & 2019 \\
\hline $\mathbf{1 7 2 6 0 . 0 7}$ & 0.67 & 0.815 & 0.136 & المتوسط \\
\hline
\end{tabular}

المصدر: جمعت وحسبت من : ( ) : قاعدة بيانات البنك الدولي، مؤشرات التنمية الاقتصاديه، . ·. . .

(Y):قاعدة بيانات المنظمة العالمية للأغذية والزراعة، FAO stat

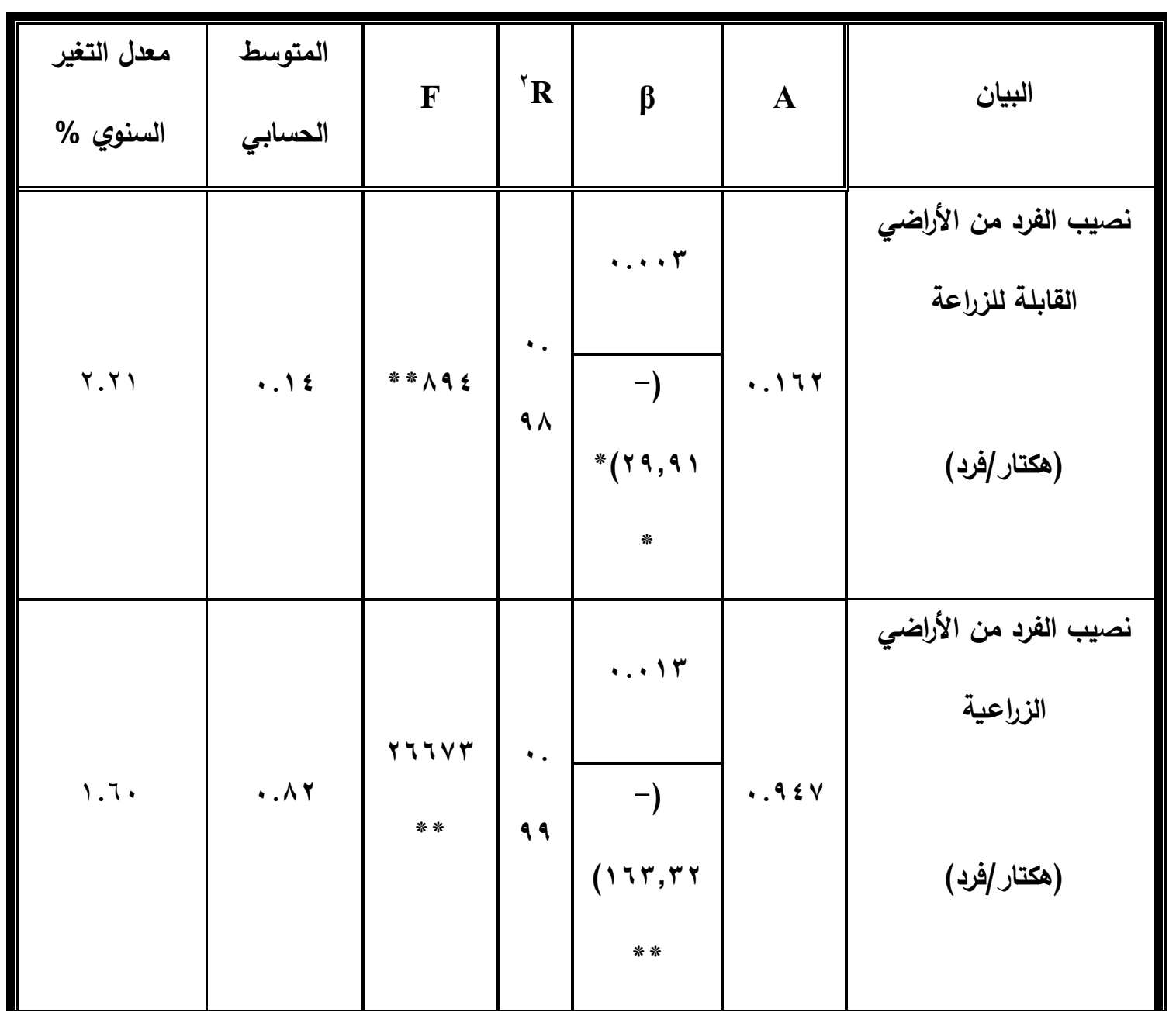

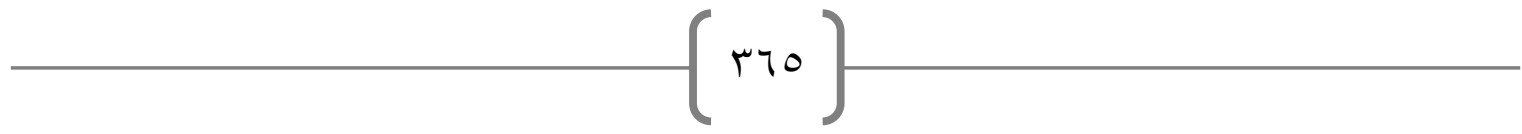




\begin{tabular}{|c|c|c|c|c|c|c|}
\hline $1.7 \varepsilon$ & . IV & 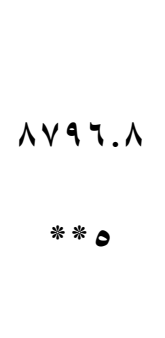 & $\begin{array}{l}\because \\
99\end{array}$ & $\begin{array}{c}\ldots+1) \\
-() \\
*(94, \vee 9\end{array}$ &.$\cdot \vee \wedge \varepsilon$ & نصيب الفرد من الموارد \\
\hline$r . . \Lambda$ & $\begin{array}{c}\text { ivrs... } \\
v\end{array}$ & $\begin{array}{c}* 10.10 \\
*\end{array}$ & $\begin{array}{l}\because \\
\leqslant \wedge\end{array}$ & $\begin{array}{l}0 \mu 1 . .40 \\
* *(r, q \wedge)\end{array}$ & $\begin{array}{l}119 \leq 9 \\
. V Y\end{array}$ & نصيب الفرد من صافى \\
\hline
\end{tabular}

جدول رقم(•) الاتجاه الزمني العام للأنصبة السكانية بعض الموارد والمؤشرات الاقتصادية في

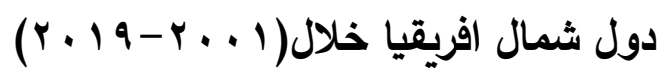

المصدر: جمعت وحسبت من :جدول رقم (؛).

ب- تطور نصيب الفرد من الموارد المائية المتجددة

يوضح الجدول رقم (ع) تطور نصيب السكان من الموارد المائية المتجددة لدول شمال

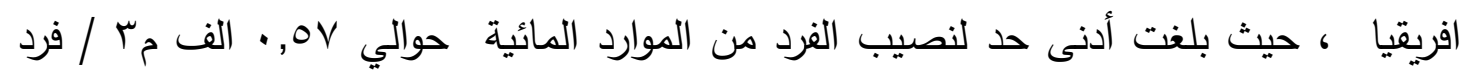
عام 9 ـ ب بينما بلغت أعلى حد لنصيب الفرد من الموارد المائية حوالي VV, • الف مج / فرد

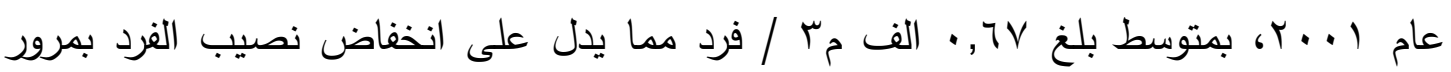
الزمن وتأثير زيادة السكان علي نصيب الفرد من تلك المورد، كما توضح المعادلة بالجدول (0) أن نصيب الفرد من الموارد المائية لدول شمال افريقيا تناقص بمعدل معنوي بلغ حوالي I| ... هكتار/فرد سنويا يعادل حوالي ؟ ج, ا \% من متوسط نصيب الفرد من الموارد المائية لمنطقة خلال فترة الدراسة، ويشير معامل التحديد)(R²) إلى أن ^,^9\% من التغيرات الحادثة في نصيب الفرد من الموارد المائية لمنطقة شمال افريقيا ترجع إلى العوامل التي يعكسها متغير الزمن. 
ج- تطور نصيب الفرد من صافي الاخل القومي :

يوضح الجدول رقم (ع) تطور نصيب السكان من صافي الدخل القومي لدول شمال افريقيا،

حيث بلغت أدنى قيمة نصيب الفرد من صافي الدخل القومي حوالي بM, • ANV دولار / فردعام

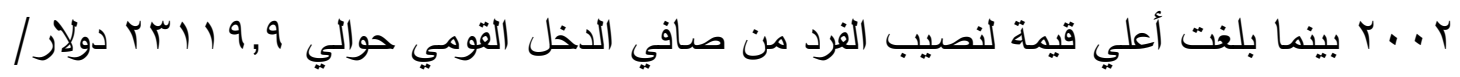

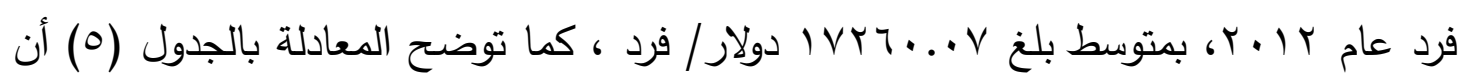
نصيب الفرد من صافي الدخل القومي لدول شمال افريقيا تزايد بمعدل معنوي بلغ حوالي

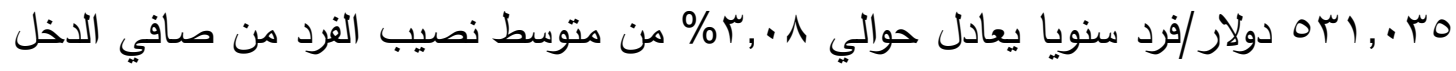
القومي للمنطقة خلال فترة الدراسة، مما يدل ارتفاع معدلات التتمية في تلك الدول، ويشير

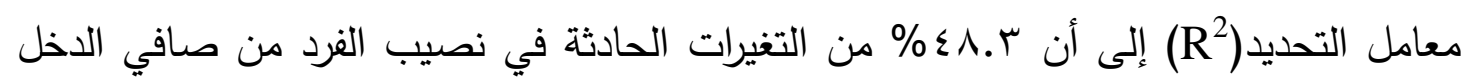
f القومي لمنطقة شمال افريقيا ترجع إلى العوامل التي يعكسها متغير الزمن. حيث بلغت قيمة

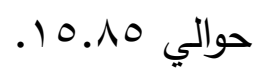
النتائج والتوصيات:

توضح نتائج البحث أنه عند دراسة: الوضع النسبي للموارد الاقتصادية تبين أن توزيع الموارد

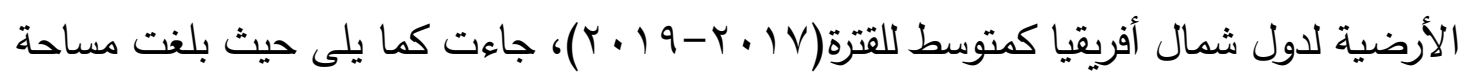
المنطقة حوالي TVNPO9 ألف هكتار وبلغت مساحة الأراضي الزراعية للمنطقة حوالي

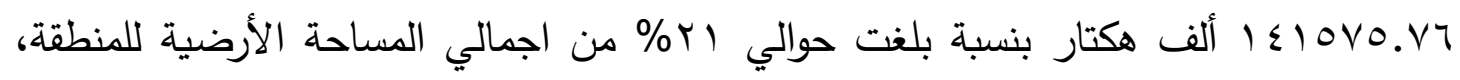
وعند دراسة المساهمة النسبية للعمالة البشرية المشتغلة في الزراعة والخدمات والصناعة لدول

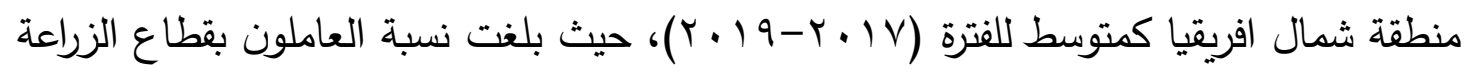
كمتوسط لدول المنطقة نحو •0 \%، بينما بلغت نسبة العاملون في قطاع الخدمات كمتوسط لدول 
المنطقة نحوهץ\%، في حين بلغت نسبة العاملون في قطاع الصناعة كمتوسط لدول المنطقة نحو \% \% وعند دراسة الأهمية النسبية للموارد المائية المتجددة لدول الثمال الافريقي كمتوسط لفترة الدراسه ، حيث شغلت مصر المرتبة الأولى بكمية بلغت حوالي OV,0 مليار مّ بنسبة بلغت نحو ه., • ٪\% من إجمالي الموارد المائية بالمنطقة، يليها في المرتبة الثانية المغرب بكمية بلغت

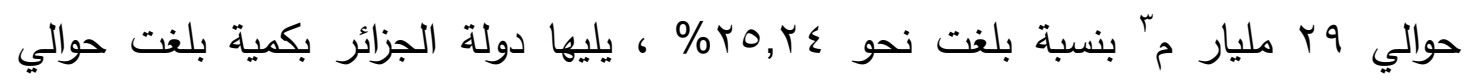

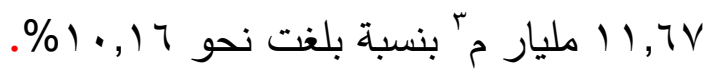

وعند دراسة نصيب الفرد من بعض الموارد والمؤشرات الاقتصادية، تبين من النتائج أن نصيب الفرد من الأراضي القابلة للزراعة في دول شمال افريقيا تتاقص بمعدل معنوي بلغ حوالي r +., • هكتار/فرد سنويا يعادل حوالي ا Y,r,\% من متوسط نصيب الفرد من الأراضي القابلة للزراعة للمنطقة خلال فترة الدراسة. وبالنسبة للموارد المائية : تبين أن نصيب الفرد من الموارد المائية لدول شمال افريقيا تناقص بمعدل معنوي بلغ حوالي ا 1 ... هكتار/فرد سنويا يعادل حوالي ؟ ج, ا \% من متوسط نصيب الفرد من الموارد المائية للمنطقة خلال فترة الدراسة.

وبدراسة نصيب الفرد من صافي الدخل القومي : تبين أن نصيب الفرد من صافي الدخل القومي لدول شمال افريقيا تزايد بمعل معنوي بلغ حوالي هب ., اسه دولار/فرد سنويا يعادل حوالي ^ • , ٪\% من متوسط نصيب الفرد من صافي الدخل القومي للمنطقة خلال فترة الدراسة، مما يدل ارتفاع معدلات التتمية في تلك الدول. بناءاً علي النتائج السابقه يوصى البحث بالأتى: 
1- ضرورة التعاون المشترك والادارة المتكاملة بين دول شمال افريقيا فيما يخص استخدام الموارد الاقتصادية، والعمل علي تبادل النفع الاقتصادي ، ولذلك لتفاوت الواضح في الموارد المتاحة لتلك الدول. ץ- رغم ظهور ارتفاع نسبى في معدلات التتمية الاقتصادية من خلال ارتفاع نصيب الفرد من صافي الدخل القومي خلال فترة الدراسة ، الا انه مازال لا يرقى بمعدلات التنمية العالمية ، فمن الضروري الاستمرارية في رفع معدلات النمو الاقتصادي لتلك الدول.

\section{المراجع والنشرات}

1- البنك الدولي ، الطبيعة المتغيرة للعمل ، تقرير عن التنمية في العالم ، 19 ـ ب. ץ- أميمــــة سعودي ، القارة الإفريقية .. مستقبل العالم ،الهيئة العامة للاستعلامات المصرية

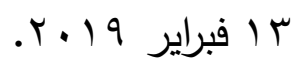
ب- فتحي ححد ابو عيانه (دكتور)، جغرافيا السكان اسس وتطبيقات، دار المعرفة الجامعية

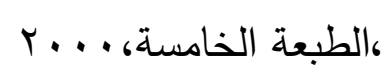

ع - قاعدة بيانات البنك الدولي، مؤشرات التنمية الاقتصاديه، • ب · r.

ه قاعدة بيانات المنظمة العالمية للأغذية والزراعة، FAO stat 